\title{
Correction to: Evaluation of RECIST, PERCIST, EORTC, and MDA Criteria for Assessing Treatment Response with Ga68-PSMA PET-CT in Metastatic Prostate Cancer Patient with Biochemical Progression: a Comparative Study
}

\author{
Manoj Gupta ${ }^{1,3} \cdot$ Partha Sarathi Choudhury $^{1} \cdot$ Sudhir Rawal $^{2} \cdot$ Harish Chandra Goel $^{3} \cdot$ S. Avinash Rao $^{4}$ \\ Published online: 17 August 2020 \\ (C) Korean Society of Nuclear Medicine 2020
}

\section{Correction to: Nucl Med Mol Imaging}

https://doi.org/10.1007/s13139-018-0548-3

The following affiliation has been added to the first author, Manoj Gupta.

Amity Centre for Radiation Biology, Amity University, Noida, Uttar Pradesh India

The original publication has now been corrected in this respect.

Publisher's Note Springer Nature remains neutral with regard to jurisdictional claims in published maps and institutional affiliations.

The online version of the original article can be found at https://doi.org/ 10.1007/s13139-018-0548-3

Manoj Gupta

docmanojgupta@yahoo.com

1 Department of Nuclear Medicine, Rajiv Gandhi Cancer Institute and Research Centre, Delhi, India

2 Department of Uro - Gynae Surgical Oncology, Rajiv Gandhi Cancer Institute and Research Centre, Delhi, India

3 Amity Centre for Radiation Biology, Amity University, Noida, Uttar Pradesh, India

4 Department of Radiology, Rajiv Gandhi Cancer Institute and Research Centre, Delhi, India 